\title{
A construção do Estatuto da Cidade e da ideia de Plano Diretor numa perspectiva histórica: discutindo a adequação destes instrumentos aos municípios de pequeno porte populacional
}

\author{
Selena Duarte Lage e Lage, \\ Lauro Luiz Francisco Filho*
}

\begin{abstract}
Resumo O Estatuto da Cidade é resultado de um longo processo de construção com influências diversas; ao longo da trajetória, o Plano Diretor passou por um processo de ressignificação. Este artigo busca refazer o caminho de construção do Estatuto da Cidade e da conotação atual do Plano Diretor. Objetiva-se compreender as ambiguidades e contradições da Lei, em especial no que se refere ao Plano Diretor, e verificar a adequação destes instrumentos aos municípios de pequeno porte populacional. Como metodologia foi realizada pesquisa documental e revisão bibliográfica. Verifica-se que as contradições e omissões relativas ao Plano Diretor expressam o embate Urbanismo x Planejamento Urbano. Tal embate e a desconsideração da variedade de arranjos socioespaciais encontrados no Brasil prejudicam especialmente os municípios pequenos.
\end{abstract}

Palavras-chave: planejamento urbano, Estatuto da Cidade, Plano Diretor, municípios de pequeno porte.

\section{La construcción del Estatuto de la Ciudad y de la idea de Plan Maestro en una pers- pectiva histórica: discutiendo la adecuación de estos instrumentos a los municipios pequeños}

\begin{abstract}
Resumen El Estatuto de la Ciudad es resultado de un largo proceso de construcción que tiene influencias diversas; en la trayectoria, el Plan Maestro pasó por un proceso de reformulación. Este artículo busca volver sobre el camino de la construcción del Estatuto de la Ciudad y de la connotación actual del Plan Maestro. El objetivo es comprender las ambigüedades y contradicciones en la Ley, especialmente con respecto al Plan Maestro, y verificar la adecuación de estos instrumentos a los municipios pequeños. Como metodología se realizó investigación documental y revisión bibliográfica. Se observó que las contradicciones y omisiones relacionadas con el Plan Maestro expresan la controversia Urbanismo x Planificación Urbana. Tal controversia y el desprecio por la variedad de arreglos socio-espaciales que se encuentran en Brasil afectan especialmente a los municipios pequeños.
\end{abstract}

Palabras clave: planificación urbana, Estatuto de la Ciudad, Plan Maestro, pequeños municípios.
The construction of the City Statute and the Master Plan's concept in a historical perspective: discussing the adequacy of these instruments to small municipalities Abstract The City Statute is the result of a long process with
diverse influences; during the process, the Master Plan's concept
has changed. This article seeks to retake the trajectory of the
construction of the City Statute and the Master Plan's current
connotation. The objective is to understand the ambiguities and
contradictions of City Statute, especially with regard to the Mas-
ter Plan, and to verify the adequacy of these instruments to small
population size municipalities. The methodology used was docu-
mentary research and bibliography review. It is verified that the
contradictions and omissions related to the Master Plan express
the Urbanism vs. Urban Planning controversy. Such a controversy
and the disregard of the variety of socio-spatial arrangements
found in Brazil are especially detrimental to small municipalities.
Keywords: urban planning, City Statute, Master Plan, small
towns. 
O

conteúdo que compõe o Estatuto da Cidade (Lei no 10.257/2001) é resultado de um longo processo de construção que tem influências de matrizes discursivas diversas. Os estudos e textos acadêmicos geralmente remontam suas origens ao Seminário Habitação e Reforma Urbana (s.HRU), ocorrido no governo João Goulart a partir da perspectiva de realização das reformas de base; ou, num momento posterior, ao Movimento Nacional pela Reforma Urbana (MNRU) e sua Emenda Popular pela Reforma Urbana, articulados no fervor da movimentação nacional pela elaboração da Carta Constitucional de 1988. Entretanto, algumas influências do texto final da Lei são encontradas em tempos mais remotos de formação do pensamento urbanístico no Brasil. Outras referências da Lei são mais recentes e apareceram ao longo do processo de negociação política a partir da assembleia constituinte.

Na trajetória de consolidação do planejamento urbano no Brasil, observa-se também um processo de ressignificação da ideia de Plano Diretor. Este instrumento está presente entre nós desde a década de 1930 e resiste em manter-se no aparato legalinstitucional do planejamento urbano brasileiro, ainda que com nova roupagem. Atualmente, pode-se dizer que o Plano Diretor constitui nosso principal instrumento de planejamento urbano, sendo regulamentado pelo Estatuto da Cidade.

Este artigo busca refazer o longo caminho de construção do Estatuto da Cidade e da conotação atual do Plano Diretor. Objetiva-se compreender as ambiguidades e contradições da Lei, em especial no que se refere ao Plano Diretor, e verificar a adequação deste instrumento aos municípios de pequeno porte populacional. Como metodologia, foi realizada revisão e análise crítica da bibliografia pertinente, destacando-se os textos legais. Dados quantitativos referentes aos municípios de pequeno porte populacional foram retirados da Pesquisa de Informações Básicas Municipais (IBGE, 2015).

O percurso de construção do Estatuto da Cidade e da ideia de Plano Diretor foi dividido em quatro etapas, explicitadas em quatro subitens. Na sequência, discute-se a ressignificação do Plano Diretor nesse percurso e sua adequação aos municípios de pequeno porte. Por fim, as considerações finais alinhavam os itens precedentes para por em foco entraves importantes à adequação dos planos diretores pós-Estatuto da Cidade aos municípios de pequeno porte populacional.

* Selena Duarte Lage e Lage é Doutoranda do Programa de Pós Graduação Arquitetura, Tecnologia e Cidade da Universidade Estadual de Campinas, ORCID <https://orcid.org/0000-00019976-1034>. Lauro Luiz Francisco Filho é Arquiteto e Urbanista, professor da Universidade Estadual de Campinas, ORCID <https://orcid.org/0000-0002-3138-0347>.

\section{A construção do Estatuto da Cidade e da ideia de Plano Diretor desde os primórdios do pensamento urbanístico no Brasil}

\author{
A formação do pensamento urbanístico no Brasil e suas principais \\ influências
}

Ao tratar da formação do pensamento urbanístico no Brasil de 1895 a 1965, Leme (2005) identifica três períodos distintos. O primeiro deles, entre 1895 e 1930, corresponde à gênese da preocupação com o urbano no Brasil. Nesta época foram propostos e 
${ }^{1}$ Leme (2005) ressalva que os planos de saneamento do final do século XIX já eram elaborados com uma visão de conjunto; no entanto, esta visão integrada só será ampliada aos planos de sistema viário e de transporte a partir dos anos 1930.
2 Segundo Villaça (2005), o termo Plan Directeur aparece pela primeira vez no Brasil no Plano Agache para a cidade do Rio de Janeiro, publicado em 1930. realizados planos de intervenção física em trechos específicos das cidades, como abertura de novas vias, implantação de infraestruturas de saneamento e ajardinamento de praças e parques.

No segundo período, de 1930 a 1950, observa-se uma nova fase de consolidação do Urbanismo enquanto área de conhecimento e de prática profissional no Brasil. Foram elaborados planos que vislumbravam o conjunto das áreas urbanas, propondo a articulação entre os bairros e as áreas centrais das cidades através de sistemas de vias e de transportes ${ }^{1}$.

No terceiro período, de 1950 a 1965, a questão urbana amplia-se, tanto no que se refere à abrangência territorial dos planos - iniciam-se os planos regionais - quanto aos temas abordados, relacionando as questões físico-funcionais a questões sociais e econômicas. Neste período, teve bastante influência o Movimento Economia e Humanismo, difundido no Brasil a partir de meados dos anos 1940 com a vinda do arquiteto francês Gaston Bardet e do padre dominicano Louis Joseph Lebret.

Em verdade, os três períodos da formação do pensamento urbanístico no Brasil podem ser relacionados a três momentos de penetração das ideias de urbanistas franceses, também identificados por Leme (2005): No início do século XX, quando o modelo de cidade difundida é a Paris das Exposições Universais; nos anos 1920-30, através dos planos de arquitetos ligados à Société Française de Urbanistes; e após a Segunda Guerra Mundial, quando forma-se uma nova geração de arquitetos, sociólogos e geógrafos que vão atuar no campo do planejamento urbano e regional com grande influência da doutrina do Movimento Economia e Humanismo.

Trata-se de uma periodização referente ao início da difusão de tais ideias no Brasil, não sendo possível identificar os períodos de sua realização na prática profissional ou mesmo do fim de tais influências. Aliás, o que se verifica é que, com o passar do tempo, essas influências coexistem e se sobrepõem na teorização e na prática do planejamento urbano no País.

Em relação ao legado da Société Française de Urbanistes, verifica-se sua repercussão na prática brasileira de planejamento urbano até os dias atuais. Esta associação de arquitetos-urbanistas foi criada em 1911, tendo como um dos seus fundadores o arquiteto Donat Alfred Agache, que mais tarde viria a desenvolver no Brasil importantes estudos, propostas e palestras sobre Urbanismo. A Société Française de Urbanistes foi influencia decisiva na aprovação, em 1919, da chamada Lei Cornudet - primeira lei francesa sobre desenvolvimento, embelezamento e extensão das cidades. Esta Lei passara a exigir das cidades francesas de mais de 20 mil habitantes planos de aménagement, embelissement et extension. Tais planos balizariam estudos para cidades em países da América Latina e da África orientados por urbanistas franceses (LEME, 2005).

No final da década de 1920, Agache manteve um escritório no Rio de Janeiro durante três anos para elaborar estudos e propostas para a cidade. A partir de estudos bastante completos, que incluíam a história econômica e social e levantamentos aerofotogramétricos do sítio, propôs o que chamou de Plan Directeur (Plano Diretor), introduzindo por aqui não só o termo ${ }^{2}$, mas também métodos e práticas de planejamento urbano. 
3 Deve-se destacar que a ideia de reconstrução da sociedade por meio da Arquitetura está no cerne da chamada Arquitetura Moderna, que começa a se desenvolver na Europa no início do século XX (FRAMPTON, 2008).
Essas ideias repercutiram na consolidação do Urbanismo no Brasil e na formação dos primeiros profissionais urbanistas brasileiros que, por sua vez, atuaram também no ensino superior, na formação de novos profissionais urbanistas. Em palestra proferida em 1929 no Instituto de Engenharia de São Paulo, o engenheiro-arquiteto e professor Anhaia Mello refere-se à Lei Cornudet da França e defende a necessidade da existência no Brasil de uma lei que obrigue todas as cidades acima de uma população determinada a organizarem um plano (MELLO, 1929).

Mais tarde, a partir do final da década de 1940, o Movimento Economia e Humanismo agrega novas questões à formação e à prática de planejamento urbano no Brasil. A difusão da ideia de planejamento urbano integrado a reformas sociais vai instigar os arquitetos brasileiros a questionar sobre sua atuação profissional e seu papel na sociedade. Distanciando-se da tradição de ver na Arquitetura apenas seus aspectos formais e artísticos, os arquitetos passarão a relacionar a arquitetura com os problemas sociais e de desenvolvimento econômico ${ }^{3}$. Esta nova postura dos arquitetos-urbanistas vai redirecionar os rumos do planejamento urbano no Brasil, com desdobramentos que alcançam os dias atuais.

\section{Nasce o ideário da Reforma Urbana}

A partir da década de 1950, à medida que a urbanização brasileira vai se acelerando e crescem os problemas urbanos, o questionamento dos arquitetos sobre seu papel social ganha força. No início da década de 1960, tal questionamento se potencializa com a atmosfera de transformações vivenciada no País, especialmente no governo João Goulart (1963-1964), quando são criadas expectativas de realização das chamadas reformas de base (RIBEIRO e PONTUAL, 2009).

Nesse contexto, o Instituto de Arquitetos do Brasil (IAB) e o Instituto de Previdência e Assistência dos Servidores do Estado (IPASE) promoveram, em 1963, o Seminário Habitação e Reforma Urbana (s.HRU). O s.HRU tinha como foco a questão habitacional, porém esta não era vista de forma isolada, mas vinculada às questões socioeconômicas do Brasil. Por isso, o evento reuniu não apenas arquitetos e engenheiros, mas profissionais de diversas formações, como sociólogos, economistas, advogados e políticos, entre outros (IAB, 1963).

Partia-se do entendimento de que os problemas habitacionais - quantitativos e qualitativos - estavam em estreita associação aos problemas da urbanização acelerada e desordenada, identificados principalmente nos grandes centros urbanos (IAB, 1963). O desenvolvimento "anárquico e incoerente das cidades" era relacionado à intensa migração campo-cidade, para a qual não estavam os espaços urbanos preparados, e também à "febre imobiliária", que provocava absurdo crescimento horizontal ou valorização artificial dos terrenos por meio do crescimento vertical (RIBEIRO e PONTUAL, 2009).

A partir desse quadro, o s.HRU propunha o que foi chamado Reforma Urbana, entendida como "conjunto de medidas estatais, visando à justa utilização do solo urbano, à ordenação e ao equipamento das aglomerações urbanas e ao fornecimento de habitação condigna a todas as famílias" (IAB, 1963, p.19). O termo parece ter surgido em associação à Reforma Agrária ${ }^{4}$, campo de luta mais amadurecido no País, e que também estava sendo debatido no 
5 As demais propostas eram: modificações na Lei do Imposto de Renda, de modo a permitir isenção de tributação para aquisição de casa própria; normas para melhoria dos conjuntos de "subhabitação"; exigência de metodologia para equacionamento da demanda habitacional quantitativa e qualitativa; providência de dados estatísticos pelo IBGE; obediência aos princípios e normas definidos no Seminário pelos órgãos governamentais que realizam programas habitacionais; alteração de legislação para criação de órgão de administração que consorciem municipalidades conformadoras de áreas de grande concentração urbana (IAB, 1963). governo João Goulart na pauta das reformas de base. Esta associação pode ser justificada em dois sentidos: 1) Devido à relação dos problemas da cidade aos problemas do campo, especialmente à migração campo-cidade; 2) Ambas discutem o acesso à terra (rural, no caso da Reforma Agrária, e urbana, no caso da Reforma Urbana) e defendem a intervenção estatal para que este acesso aconteça de forma justa e equilibrada.

Assim, ressalta-se que o termo "Reforma Urbana" não está relacionado à reforma de cidade, no sentido de embelezamento ou modernização física. É certo que a questão física é considerada, especialmente no que se refere ao ordenamento territorial e ao provimento de equipamentos e serviços urbanos, porém não é o foco do debate. O tema central da Reforma Urbana é o acesso a terra ou solo urbano, de modo a viabilizar uma distribuição mais igualitária dos benefícios da urbanização. Por isso, as discussões e propostas levantadas no s.HRU remetiam a medidas e instrumentos político-jurídicos e não estavam relacionadas ao desenho urbano.

O documento final resultante do s.HRU colocava nove propostas, destacando-se: 1) promulgação de providências legais e administrativas relacionadas com as reformas de base, imprescindíveis à solução dos problemas levantados; 2) mudança constitucional para permitir ao Governo formas outras de indenização (não apenas em dinheiro) por desapropriação em caso de interesse social; 3) envio ao Congresso Nacional de projeto de lei contendo os princípios da Política Habitacional e Reforma Urbana aprovados no Seminário, em especial a criação de órgão central federal executor da Política Habitacional e Urbana; 4) criação de órgão de administração que consorciem as municipalidades constituintes de aglomerações urbanas (IAB, 1963) ${ }^{5}$.

O presidente João Goulart incorporou muitas das recomendações do s.HRU a seu plano de governo. No entanto, o golpe militar daquele ano vai interromper o debate e, por ora, dissipar as esperanças de realização das reformas de base.

\section{Do Seminário de 1963 à Constituição de 1988}

Logo no início do Regime Militar, as propostas do s.HRU relacionadas à política habitacional e ao planejamento urbano foram parcialmente implementadas com a Lei n 4.380/64, que instituiu o Serviço Federal de Habitação e Urbanismo (SERFHAU) e o Banco Nacional de Habitação (BNH). No entanto, a política de financiamento habitacional adotada e os planos de desenvolvimento local integrado elaborados por incentivo do SERFHAU não foram capazes de conter a especulação imobiliária, a distorção dos preços das terras urbanas e o crescimento exagerado e sem infraestrutura adequada das grandes cidades e áreas metropolitanas. A partir de 1974, com a extinção do SERFHAU, avaliava-se a necessidade de enfrentamento dos problemas urbanos, especialmente dos grandes centros, a partir de uma nova abordagem (CARDOSO, 1997).

Nessa conjuntura, as discussões relacionadas à Reforma Urbana foram retomadas em 1977, ainda sob a ditadura militar, com a criação da primeira versão de uma Lei Federal de Desenvolvimento Urbano (LDU), elaborada no âmbito do Conselho Nacional de Desenvolvimento Urbano. Os propósitos dessa lei tinham como referência as discussões do s.HRU, em especial dotar o Poder Público de instrumentos para disciplinar a expansão urbana, controlar o uso do solo e combater os processos especulativos prevalecentes nas grandes cidades. 
A publicação do documento gerou de imediato uma manifestação de repúdio pelo setor imobiliário, provocando debates na imprensa. Com todas as resistências e pressões, o projeto de lei ( $\mathrm{PL}$ ) foi enviado à Câmara dos Deputados, já numa versão mais branda, apenas em 1983, como (PL) n 775/83 (CARDOSO, 1997).

O PL n 775/83 colocava como uma das diretrizes na promoção do desenvolvimento urbano a adequação da propriedade imobiliária urbana à sua função social, mediante oportunidade de acesso à propriedade urbana e à moradia; justa distribuição dos benefícios e ônus decorrentes do processo de urbanização; correção das distorções da valorização da propriedade urbana; regularização fundiária e urbanização específica de áreas urbanas ocupadas por população de baixa renda; e adequação do direito de construir às normas urbanísticas. Para tal, o documento apostava nos planos de desenvolvimento urbano, elaborados nos âmbitos nacional, estadual, metropolitano e municipal, e nas leis de parcelamento, uso e ocupação do solo, que deveriam ser elaborados em âmbito municipal. Determinava que tais leis definissem o tipo de uso, a taxa de ocupação e o índice de aproveitamento do terreno. Também determinava que as áreas urbanas e de expansão urbana fossem delimitadas por lei municipal de forma a abrangerem, no máximo, a superfície necessária à localização da população urbana e de atividades previstas para os dez anos subsequentes. Como instrumentos jurídicos e tributários, instituía: IPTU progressivo; Contribuição de melhoria; Parcelamento, edificação ou utilização compulsórios; Direito de preempção; Direito real de concessão de uso; Direito de superfície; e Transferência do direito de construir (BRASIL, 1983).

As várias críticas e resistência ao Projeto, bem como o início dos debates em torno da nova Carta Constitucional, que passaram a polarizar as atenções e os interesses já em 1986, resultaram no seu "engavetamento". No entanto, o processo constituinte será um importante catalisador para um terceiro momento de retomada da discussão, desta vez endossada por matriz teórico-conceitual de inspiração marxista.

Tal matriz teórica, difundida nas universidades brasileiras a partir dos fins da década de 1970, entende a cidade como produto da estrutura social, portanto resultado da dinâmica da acumulação capitalista, das políticas públicas e das práticas sociais, simultaneamente. Nessa perspectiva, a questão urbana está fortemente vinculada à política, e os movimentos sociais urbanos são exaltados como sujeitos capazes de alterar a correlação de forças na luta de classes, pois apresentam demandas que contrariam a lógica de atuação do Estado autoritário capturado pelos interesses capitalistas (CARDOSO, 1997; SANTOS JR., 1995).

Imbuídos dessas ideias e a partir da possibilidade de apresentação de emendas constitucionais populares, as universidades, entidades profissionais, sindicatos, ONGs e movimentos populares ligados à questão urbana se articularam e constituíram o Movimento Nacional pela Reforma Urbana (MNRU), responsável pela elaboração da Emenda Popular pela Reforma Urbana. Desacreditados da neutralidade do planejamento urbano tecnocrático, a proposta do MNRU negava os planos urbanos e apostava na participação popular na gestão das cidades e nos instrumentos jurídicos e tributários de limitação ao exercício do direito de propriedade. Também dava diretrizes gerais para as políticas de moradia, transportes e serviços urbanos, a serem garantidos pelo Estado (CARDOSO, 1997). 
No que se refere aos instrumentos político-jurídicos, a emenda popular claramente se inspirou na LDU, porém, apresentava uma concepção mais ampliada de direitos urbanos e enfatizava a importância da participação popular e da ideia de gestão, em detrimento da ideia de planejamento relacionada à definição de planos. Conforme colocado por Cardoso (1997, p. 90), "a grande diferença talvez esteja nas ênfases diferenciadas emprestadas pelos dois documentos; uma, ao papel do planejamento urbano (a LDU); a outra, à participação popular (a emenda popular)."

Após muitos debates e negociações na assembleia constituinte, o capítulo constitucional referente à política urbana (Capítulo II - Da Política Urbana, artigos 182 e 183) mostrou-se ambíguo. Na verdade, trata-se de um mix de diferentes matrizes discursivas relativas à questão urbana. O princípio da função social da propriedade foi consagrado e instituiu-se também o princípio da função social da cidade; todavia, a definição e realização desses princípios ficaram vinculadas ao Plano Diretor, a ser aprovado em âmbito municipal. Tornou-se obrigatória a elaboração de planos diretores para cidades com mais de 20 mil habitantes. Em relação a tal corte populacional (20 mil habitantes), ressalta-se que é o mesmo utilizado na Lei Cornudet promulgada na França em 1919.

Como instrumentos jurídicos e tributários, o capítulo "Da Política Urbana" instituiu o Parcelamento ou edificação compulsórios, IPTU progressivo, e desapropriação com pagamento em títulos da dívida pública, a serem aplicados sucessivamente (Art. 182), e também o Usucapião urbano (Art. 183). Porém, estabeleceu a necessidade de uma regulamentação federal de orientação da política de desenvolvimento urbano, definida como atribuição exclusiva do município. No que se refere à participação popular, o Capítulo não traz diretrizes, mas o texto constitucional consagra a participação como constitutiva da noção de soberania popular e estabelece mecanismos de participação direta.

Assim, a Constituição de 1988 consolidou o Plano Diretor como principal instrumento da política de desenvolvimento urbano, deslocando o debate para a esfera local. Ao mesmo tempo, colocou a necessidade de regulamentação federal para direcionamento e ratificação das normas municipais.

\section{Da Constituição de 1988 ao Estatuto da Cidade}

Com a ampliação da autonomia política dos municípios, em especial a definição da responsabilidade municipal sobre o ordenamento e controle do solo urbano, os reformistas depositaram suas esperanças nas leis orgânicas e planos diretores municipais. Paralelamente, uma frente de mobilização seguiu lutando pela regulamentação federal do capítulo constitucional da política urbana.

Segundo De Grazia (2002), logo após a aprovação da Constituição de 1988, o Senador Pompeu de Souza (PMDB) apresentou o projeto de lei denominado "Estatuto da Cidade". O projeto foi aprovado rapidamente pelo Senado Federal e, ainda em 1990, começou a tramitar na Câmara dos Deputados como PL nº 5.788/90.

Verifica-se que a versão original do PL apresentava redação mais extensa e abrangente de conteúdo que a do Estatuto da Cidade aprovado em 2001. Entre os temas tratados no PL não disponíveis no Estatuto podemos citar as diretrizes relacionadas a políticas 
60 FNRU foi criado durante a tramitação da emenda popular constitucional e seguiu atuando como herdeiro das iniciativas e propostas do Movimento Nacional pela Reforma Urbana.
7 Ressalta-se que esta determinação também estava presente no projeto da LDU. setoriais, a equipamentos urbanos e comunitários e a Regiões Metropolitanas e Aglomerações Urbanas (BRASIL, 1990).

Desde o início, os atores e entidades que representavam os proprietários de terra e os empresários da construção civil e do setor imobiliário tentaram impedir a tramitação do PL (assim como ocorrido com o projeto da LDU). Para atrasar o processo, as articulações opositoras fizeram com que fosse analisado na Câmara pela Comissão de Economia, Indústria e Comércio (CEIC) e pela Comissão de Defesa do Consumidor, Meio Ambiente e Minorias (CDCMAM), além da Comissão de Desenvolvimento Urbano e Interior (CDUI) e da Comissão de Constituição e Justiça (CCJ) (DE GRAZIA, 2002).

O PL ficou quase sete anos na CEIC, depois um ano na CDCMAM, um ano na CDUI e mais um ano na CCJ. Ainda houve recursos levados ao Plenário da Câmara, depois voltou ao Senado, onde passou pela Comissão de Assuntos Sociais e por Plenária, e finalmente seguiu para sanção pelo Presidente da República, em julho de 2001. Ao todo, foram onze anos de muitas tensões e resistências (DE GRAZIA, 2002). A autora destaca a contribuição do Fórum Nacional de Reforma Urbana (FNRU) ${ }^{6}$ para a aprovação final do PL, acompanhando permanentemente o processo, ainda que enfrentando dissensos internos e críticas externas.

Ao longo do processo de tramitação, o projeto foi modificado em vários pontos. Em relação aos instrumentos de política urbana, De Grazia (2002) coloca que o "Estudo Prévio de Impacto de Vizinhança" foi acrescentado pela Comissão de Meio Ambiente, e os instrumentos "Outorga Onerosa de Construir" e "Operações Urbanas Consorciadas" foram propostos pelas entidades imobiliárias no relatório da Comissão de Economia. A autora afirma que a versão final da lei "ficou mais precisa e mais completa em muitos artigos, deu-se consequência a algumas diretrizes, foram acrescentadas outras matérias relevantes para os setores populares" (DE GRAZIA, 2002, p.27). Porém, ao comparar o texto original do PL com a Lei aprovada, nota-se que foram excluídos itens importantes referentes à Função Social da Propriedade, a Regiões Metropolitanas e Aglomerações Urbanas, ao Plano Diretor e à criação do Conselho Nacional de Política Urbana.

Especificamente no que se refere ao Plano Diretor (Capítulo IV do PL n 5.788/90 e Capítulo III da Lei $\left.n^{\circ} 10.257 / 01\right)$, o texto final é bem mais pobre de exigências. O PL definia como conteúdo mínimo do PD: Sistema de acompanhamento e controle; Programa de expansão urbana; Programa de uso do solo urbano; Programa de dotação urbana - equipamentos urbanos e comunitários; e Código de Obras e Edificações. Assim, o PL estipulava que o PD definiria parâmetros e normas de uso e ocupação do solo urbano; determinava, inclusive, que "enquanto não for aprovado o Plano Diretor, o índice para aproveitamento máximo de construção será de uma vez a área do terreno" (BRASIL, 1990, Parágrafo único do Art.41)7. O texto final aprovado define como conteúdo mínimo do PD, além do sistema de acompanhamento e controle, os instrumentos "Direito de Preempção", "Outorga Onerosa do Direito de Construir", "Operações Urbanas Consorciadas", Transferência do Direito de Construir" e "Parcelamento, Edificação ou Utilização Compulsórios", sendo que apenas no caso deste último há a exigência de delimitação das áreas onde poderá ser aplicado.

Assim, nota-se que a versão final do Estatuto da Cidade descolou do Plano Diretor os instrumentos vinculados a parâmetros de uso e ocupação do solo, deixando a 
8Em 2012, a Lei n 12.608 também incluiu na obrigatoriedade de elaboração de plano diretor as cidades presentes no cadastro nacional de municípios com áreas suscetíveis à ocorrência de deslizamentos de grande impacto, inundações bruscas ou processos geológicos ou hidrológicos correlatos (BRASIL, 2012). critério dos municípios a implementação de normas complementares para instituição de tais parâmetros. Ao mesmo tempo, a versão final da Lei ampliou a gama de municípios obrigados a elaborar Plano Diretor, incluindo, além daqueles com mais de 20 mil habitantes, os integrantes de regiões metropolitanas, de áreas de interesse turístico e inseridos em área de influência de empreendimentos de impacto ambiental, independentemente do porte populacional ${ }^{8}$. Além disso, determinou que o Plano Diretor deve englobar todo o território dos municípios, ou seja, suas áreas urbanas e rurais. Dessa forma, verifica-se uma expectativa de maior abrangência do Plano Diretor, tanto territorialmente quanto em relação aos temas a serem abordados, ao mesmo tempo em que são excluídos de seu conteúdo mínimo instrumentos autoaplicáveis na prática da gestão urbana.

\section{A ressignificação do Plano Diretor e sua adequação aos mu- nicípios de pequeno porte populacional}

\section{A nova conotação do Plano Diretor pós-Constituição de 1988}

Proveniente do urbanismo francês e inserido no Brasil ainda na década de 1930, o Plano Diretor persistirá em manter-se no aparato legal-institucional do planejamento urbano brasileiro. Todavia, a partir da Constituição de 1988, ganhou uma conotação bastante diferente da sua acepção original.

Anteriormente à década de 1970, os planos diretores das cidades tratavam de assuntos concernentes ao traçado viário, expansão urbana, usos e ocupação do solo. Especialmente nos casos das cidades de menor porte, não era raro o uso de perspectivas gráficas para exprimir o modelo estético-espacial desejado para a cidade. O artigo intitulado "Planos Diretores para as cidades pequenas e médias do Brasil", publicado em 1964 no $n^{\circ} 22$ da Revista Arquitetura, descreve como elementos essenciais de um plano diretor: a) um conjunto de desenhos técnicos que definem o zoneamento de usos e de densidades, o sistema viário, a sistematização dos espaços livres de recreação, de reserva e de separação física e a localização e pré-dimensionamento dos serviços públicos; b) uma programação de obras públicas com um esquema de funcionamento; c) uma legislação institucionalizando as normas, regulando as mudanças de usos dos edifícios e terrenos, regulando o parcelamento da terra, regulando a ocupação do espaço e as construções, aprovando o plano diretor e determinando as condições de sua revisão periódica (IAB, 1964).

A partir da década de 1970, o SERFHAU, inspirado no Comprehensive Planning, vai introduzir a ideia de planejamento integrado (que busca estabelecer princípios ordenadores referentes a todas as políticas municipais) e os planos diretores se tornaram ainda mais abrangentes de conteúdo. Cada vez mais se abandona a ideia de cidade enquanto unidade fechada para apreendê-la enquanto processo inserido num contexto mais amplo. Não obstante, os planos continuaram sendo definidos de forma tecnocrática, contando com amplo conjunto de documentos técnicos e legais não debatidos com a sociedade nem com seus representantes.

A partir da Constituição de 1988, os planos diretores ganham uma conotação nova, eminentemente política. Nesta nova orientação, torna-se obrigatória sua legitimação pela sociedade civil a partir da aprovação em lei pela Câmara Municipal. Além disso, 
começa a haver pressão para a discussão dos documentos diretamente com a população via associações de classe ou de bairro. Posteriormente, o Estatuto da Cidade vai tornar a demanda por participação popular direta obrigatória na elaboração dos planos diretores, através de audiências públicas, debates e publicidade dos documentos e informações.

A politização dos planos diretores pós-Constituição de 1988 vai além da participação popular, pois também está relacionada à busca por justiça social e efetivação da função social da propriedade. Estes ideais, conforme acreditava o MNRU, seriam alcançados por meio de instrumentos jurídicos e tributários, dos quais a Constituição de 1988 instituiu o Parcelamento ou edificação compulsórios, IPTU progressivo no tempo e Desapropriação com pagamento em títulos, a serem aplicados sucessivamente.

Na prática, a aplicação dos instrumentos ficou subordinada ao Plano Diretor, que se tornou obrigatório para as cidades com mais de 20 mil habitantes. A Constituição, no entanto, não esclareceu as diretrizes para elaboração dos planos diretores, tampouco definiu seu conteúdo, ficando então a critério de cada município. Em relação ao planos diretores pós-Constituição, informa-nos Cardoso (1997) que, de modo geral, podem ser considerados "integrados", uma vez que buscam estabelecer princípios ordenadores para grande parte das políticas municipais; em relação a diretrizes de uso e ocupação do solo, determinam princípios gerais, a serem detalhados e aprofundados em legislação complementar.

Especialmente a partir da aprovação do Estatuto da Cidade, o foco dos planos diretores (assim como de suas análises) volta-se para os vários instrumentos jurídicos e tributários regulamentados pela Lei. De modo geral, os planos diretores pós-Estatuto da Cidade têm sido compostos de diretrizes gerais referentes a políticas municipais diversas (a depender da ênfase ou orientação de cada Plano Diretor) e dos instrumentos instituídos como conteúdo mínimo. Sobre os planos diretores pós-Estatuto da Cidade, a pesquisa do Ministério das Cidades de 2011 constatou que um dos principais problemas identificados nos planos analisados é que diversas diretrizes e instrumentos não estão adequadamente demarcados no território. Segundo o documento, isso evidencia "o descolamento dos propósitos do plano com o território municipal e a fragilidade de estratégias de desenvolvimento urbano pretendidas nesses Planos Diretores" (SANTOS JR. e MONTANDON, 2011, p.36).A Resolução n 34 do Conselho das Cidades, de 2005, pretendeu melhor definir o conteúdo mínimo dos planos diretores. A ênfase continuou nos instrumentos político-jurídicos, mas passou a exigir a demarcação territorial dos mesmos, visando à autoaplicação pelos planos diretores (BRASIL, 2005). Entretanto, a exigência parece não ter surtido efeito. Não é raro encontrar planos diretores sem um único mapa ou figura de orientação espacial.

Observa-se que, apesar do aparato legal existente, não há clareza, nem mesmo entre profissionais da área ou no meio acadêmico, sobre o que se esperar de um Plano Diretor. O Estatuto da Cidade e a Resolução $n^{\circ} 34$ do Conselho das Cidades definem o conteúdo mínimo dos planos diretores, cabendo às municipalidades identificar demandas outras pertinentes à realidade local. Não obstante, os planos diretores, ao focarem em diretrizes gerais e na instituição de instrumentos desprovidos de demarcação territorial, estão afastando-se dos aspectos ligados à forma urbana e sua funcionalidade. Estes aspectos ficam relegados a outras leis e planos, que, muitas 
$9 \mathrm{Em} 10$ de abril de 2019, este cadastro ainda não havia sido publicado nos sítios eletrônicos do Governo Federal.

\footnotetext{
10 Apesar da Outorga Onerosa do Direito de Construir ser muitas vezes associada ao Solo Criado - instrumento pensado no âmbito da Reforma Urbana -, este se difere do primeiro porque pressupõe a compra de potencial construtivo a partir do direito de construir igual a uma vez à área do terreno, enquanto a Outorga Onerosa permite uma flexibilização do potencial construtivo definido em lei.
}

vezes, não são elaborados pelo poder público ou, uma vez elaborados anteriormente ao Plano Diretor, permanecem desalinhados às diretrizes deste.

Em 2012, a Lei n 12.608 incluiu alguns acréscimos ao Capítulo III ("Do Plano Diretor") do Estatuto da Cidade que, de certa forma, visam minimizar essa deficiência em casos específicos. Para os municípios incluídos no cadastro nacional de municípios com áreas suscetíveis à ocorrência de deslizamentos de grande impacto, inundações bruscas ou processos geológicos ou hidrológicos correlatos ${ }^{9}$, passou a ser exigido como conteúdo mínimo dos seus planos diretores parâmetros de parcelamento, uso e ocupação do solo e mapeamentos das áreas suscetíveis, entre outras exigências (BRASIL, Lei n 10257, Art. 42-A). Também no caso de municípios que pretendam ampliar o perímetro urbano, estes deverão elaborar projeto específico que contenha, no mínimo, demarcação de novo perímetro urbano e definição de parâmetros de parcelamento, uso e ocupação do solo, entre outras exigências (BRASIL, Lei n 10257, Art. 42-B).

\section{A adequação do Plano Diretor pós-Estatuto da Cidade aos municípios de pequeno porte populacional}

De modo geral, o conteúdo mínimo do Plano Diretor definido pelo Estatuto da Cidade ficou restrito a alguns dos instrumentos político-jurídicos criados no âmbito do ideário da Reforma Urbana (Parcelamento, Edificação ou Utilização Compulsórios; Direito de Preempção; Transferência do Direito de Construir) e outros inseridos na Lei por pressões do setor imobiliário (Outorga Onerosa do Direito de Construir ${ }^{10}$; Operações Urbanas Consorciadas). Em ambos os casos, são instrumentos pensados para a realidade dos grandes centros urbanos. O movimento pela Reforma Urbana nasceu em e para as grandes cidades brasileiras (especialmente Rio de Janeiro e São Paulo), desde sempre focando suas preocupações no acesso à terra urbana, que é de fato mais disputado nos grandes centros, acarretando em graves problemas habitacionais e de especulação imobiliária; também os setores imobiliários se interessam principalmente pelas grandes cidades, onde a renda e lucro imobiliários são maiores. Contraditoriamente, o Estatuto da Cidade aumentou a gama de municípios obrigados a elaborar seus planos diretores, com a inclusão de municípios com menos de 20 mil habitantes.

O recorte populacional de 20 mil habitantes definido na Constituição de 1988 para obrigatoriedade de elaboração do Plano Diretor desde então já se mostrava distorcido em relação à nossa realidade de país periférico, cujas políticas de desenvolvimento a partir da década de 1950 resultaram em aguda polarização econômica e populacional, bem mais acentuada que a dos países centrais do capitalismo. Esta distorção não foi revista pelo Estatuto da Cidade que, pelo contrário, provocou sua ampliação ao exigir de todos os municípios o mesmo conteúdo mínimo do Plano Diretor sem levar em conta a variedade de arranjos socioespaciais encontrados no País.

Nos casos dos municípios de pequeno porte populacional, os instrumentos definidos como conteúdo mínimo pelo Estatuto da Cidade dificilmente são adequados à sua realidade. Agrava a situação o fato de que estes municípios geralmente têm o Plano Diretor como único instrumento de planejamento e gestão ligado à questão territorial. Segundo dados da Pesquisa de Informações Básicas Municipais (IBGE, 2015), entre os municípios com menos de 20 mil habitantes, aproximadamente $60 \%$ têm legislação sobre parcelamento do solo, sendo que quase 1/3 (30,5\%) dispõe desta legislação como 
parte integrante do Plano Diretor; apenas 57\% têm legislação sobre zoneamento ou uso e ocupação do solo, sendo que quase a metade $(41,2 \%)$ dispõe desta legislação como parte integrante do Plano Diretor.

Sendo o Plano Diretor, normalmente, restrito ao conteúdo mínimo definido no Estatuto da Cidade, privam-se estes municípios de planos e normas para lidar com suas demandas tanto no espaço intra-urbano quanto no que se refere à sua inserção regional.

No caso dos municípios de pequeno porte, sabe-se que o provimento de bens e serviços de mais alto nível só se torna possível a partir de articulações intermunicipais que os viabilizem economicamente. No entanto, o Estatuto da Cidade também não apresenta diretrizes e instrumentos de articulação das políticas setoriais em âmbito regional, para além da estrutura federativa de competências. Em relação a essa questão, a Lei de Consórcios Públicos publicada em 2005 (Lei n 11.107/05) pode ser vista como um avanço, uma vez que dispõe de normas para consórcios entre os entes federativos que visem interesses comuns. Segundo dados da Pesquisa de Informações Básicas Municipais (IBGE, 2015), quase 53\% dos municípios de até 20 mil habitantes participam de algum consórcio público. A grande maioria deles concentra-se na área da Saúde (33,2\%), seguida por aqueles relacionados a Manejo de resíduos sólidos $(14,7 \%)$ e Meio Ambiente (10,2\%).

A Constituição de 1988 e o Estatuto da Cidade, ao estabelecerem a municipalização de várias competências, não determinaram as atribuições em questões que exigem tratamento regional; tampouco deram diretrizes norteadoras que viabilizassem o equacionamento de problemas e demandas intermunicipais.

\section{Urbanismo x Planejamento Urbano}

Considerando o processo de construção do Estatuto da Cidade e da ideia de Plano Diretor desde os primórdios do pensamento urbanístico no Brasil, notamos ao longo da trajetória a passagem de uma abordagem mais focada em aspectos formais e funcionais das cidades, para uma visão mais abrangente e complexa do espaço urbano. A primeira abordagem estaria relacionada ao campo do Urbanismo, enquanto a segunda se inscreve no campo do Planejamento Urbano, partindo do pressuposto de que Urbanismo e Planejamento Urbano são disciplinas ou ciências distintas (COSTA,

11 No Brasil, as duas áreas de conhecimento são recorrentemente tomadas como sinônimas, de modo que, não raro, vemos o uso dos dois termos - Urbanismo e Planejamento Urbano - de forma indiscriminada. Entretanto, Costa (2012) e Souza (2016) defendem serem estas ciências distintas, ainda que complementares.
2012; SOUZA, 2006). ${ }^{11}$

Conforme coloca Costa (2012), a área de conhecimento voltada à ordenação territorial, cujas raízes remontam às transformações ocorridas a partir da Revolução Industrial, recebeu designações diversas em cada país: Urbanización (em espanhol), Urbanisme (em francês), Town Planning (mais empregado na Inglaterra), City Planning (mais empregado nos EUA), Städtebau (em alemão), Urbanística (em italiano). O termo Urbanismo, proveniente da França, teria, pelo menos em sua acepção original, uma profunda vinculação com o que, no passado, chamava-se "arte urbana". Assim, o Urbanismo estaria relacionado principalmente a questões formais e estéticas, portanto, pertenceria à tradição do saber arquitetônico. Nesta perspectiva, a cidade pode ser pensada como uma unidade fechada e a partir de modelos espaciais preestabelecidos por aspectos de ordem puramente técnica. 
Diferentemente, o Planejamento Urbano, de origem anglo-saxão, não se propõe a pensar modelos de cidade, mas sim a equacionar as tensões e interesses inerentes à dinâmica socioespacial de uma determinada localidade. "Neste sentido, o planejamento urbano é mais uma resposta às demandas sociais, do que uma mera aplicação de conceitos, modelos urbanísticos e técnicas, a fim de construir as cidades de 'forma bela'" (COSTA, 2012, p.150). Ao lidar com os embates dos interesses setoriais e de classes, o planejamento urbano configura-se, desde sempre, como uma atividade política e multidisciplinar (e não atribuição de um único profissional especialista), pois as questões a serem equacionadas são de ordem e natureza diversas. A cidade, subordinada a uma série de relações socioespaciais, não é tomada como unidade isolada, nem fechada em si, mas antes uma parcela que compõe, faz parte de um todo maior - o território.

Assim, as diferenças entre Urbanismo e Planejamento Urbano não são apenas de origem etimológica, mas embasadas na própria natureza e objetivos das disciplinas. Entretanto, mais do que antagônicas, Costa (2012) defende serem disciplinas complementares. Em verdade, tanto Costa (2012) quanto Souza (2006) afirmam que o Planejamento Urbano inclui o Urbanismo. Ou seja, as preocupações formais, estéticas e funcionais do Urbanismo são partes integrantes de um campo de ação mais amplo - o Planejamento Urbano.

Esclarecidas as diferenças entre os termos, parece-nos evidente a transição no Brasil de uma matriz inicialmente mais relacionada ao Urbanismo para uma matriz de maior vinculação ao Planejamento Urbano. Claro que não se pode deixar de mencionar que o próprio conceito de Urbanismo nunca fora homogêneo e foi se tornando mais abrangente à medida que se distanciava da sua concepção inicial, aproximando-se do conceito de Planejamento Urbano (COSTA, 2012). Também o conceito de Planejamento Urbano não pode ser considerado homogêneo e sofreu transformações em diferentes épocas e sociedades. No caso do Brasil, o ideário da Reforma Urbana pretendeu sua reconceituação como instrumento de democratização da gestão, em contraposição ao planejamento urbano autoritário e tecnocrático vivenciado no País à época da ditadura militar (SANTOS JR., 1996).

De qualquer forma, interessa-nos o fato de que no Brasil, ao longo do processo de consolidação institucional do planejamento urbano, as preocupações de caráter estético, formal e funcional do urbano parecem ter sido relegadas a segundo plano em relação aos instrumentos da política urbana. Este fato pode ser constatado pelas mudanças ocorridas em relação à ideia e conteúdo do Plano Diretor. Na transição identificada da matriz do Urbanismo para a matriz do Planejamento Urbano, os planos diretores estão afastando-se cada vez mais do campo do Urbanismo, não tratando de aspectos relacionados à forma urbana e sua funcionalidade.

Para Villaça (2005), o Plano Diretor composto de "generalidades", sem condições concretas de aplicação, não passa de ferramenta das classes dominantes ("planodiscurso") para ocultar seu fracasso e culpa em resolver os problemas urbanos, ao passo que mantêm o status quo. Para o autor, o Zoneamento, que é menos pretensioso que o Plano Diretor ao tratar apenas do controle do uso e ocupação do solo, vem se executando através de leis autoaplicáveis e se mostra mais eficiente em seus propósitos. 
Tal embate entre Zoneamento e Plano Diretor muitas vezes é reduzido à oposição entre os paradigmas técnico e político do planejamento urbano. No entanto, não se trata aqui de discutir esta oposição, visto que tanto o Planejamento Urbano quanto o Urbanismo podem realizar-se em ambos os paradigmas. O que se pretende é revelar que o embate entre o paradigma técnico e o político, aqui no Brasil, parece ter se confundido com o embate entre Urbanismo e Planejamento urbano.

Tanto Costa (2012) quanto Souza (2006) defendem que o Urbanismo é parte integrante do Planejamento urbano, ou seja, o primeiro pode ser considerado um subconjunto ou subatribuição do segundo. Portanto, estes campos do conhecimento não deveriam rivalizar-se, mas sim complementar-se.

\section{Considerações finais}

A construção do Estatuto da Cidade teve influências de matrizes discursivas diversas que fizeram parte da formação e consolidação institucional do planejamento urbano no Brasil. Nesse processo, o Plano Diretor, que desde a década de 1930 tem se mantido como importante instrumento do planejamento urbano brasileiro, deslocou-se da sua conotação inicial relacionada a questões estéticas e funcionais das cidades para a esfera do direito urbanístico de abordagem territorial.

No que se refere ao espaço intraurbano, verifica-se que a atual redação do Estatuto da Cidade relega as questões de urbanismo a segundo plano, e isso tem prejudicado especialmente os municípios de pequeno porte, que não têm recursos humanos, técnicos e financeiros para elaboração de outros planos e normas relacionadas à forma, funcionalidade e estética urbanas. Por outro lado, numa escala mais abrangente, o Estatuto da Cidade não apresenta diretrizes e instrumentos de articulação das políticas setoriais em âmbito regional, essenciais ao provimento de serviços urbanos mais qualificados em municípios de poucos recursos financeiros.

O que se observa é que o deslocamento do Plano Diretor para a esfera do direito urbanístico abandonou as pequenas cidades à sorte imprevisível da falta de parâmetros físico-funcionais e, ao mesmo tempo, não conseguiu contemplar devidamente sua aspiração por uma abordagem territorial mais abrangente. No jogo de forças da construção e aplicação do Estatuto da Cidade, a politização do planejamento urbano, defendida pela esquerda progressista, tem sido utilizada pelas forças conservadoras para torná-lo ineficiente.

Contudo, deve-se ressaltar que as ambiguidades e omissões das determinações legais relativas ao Plano Diretor expressam, mais do que a oposição entre planejamento tecnocrático e planejamento politizado, o embate Urbanismo x Planejamento urbano. Assim, não se defende aqui a volta do planejamento tecnocrático e autoritário, mas a consideração das questões de urbanismo inseridas no planejamento politizado.

\section{Referências bibliográficas}

BRASIL. Câmara dos Deputados. Projeto de Lei n. 775, de 1983. Dispõe sobre os objetivos e a promoção do desenvolvimento urbano e dá outras providências. Disponível em: <http:// www.camara.gov.br/proposicoesWeb/prop_mostrarintegra;jsessionid=C49902CDCEC06 
5DC98D766B4AE08BC03. proposicoesWebExterno2?codteor=1168941\&filename=Doss ie+-PL+775/1983>. Acesso em: 20 jan. 2018.

BRASIL. Câmara dos Deputados. Projeto de Lei n. 5788, de 1990. Estabelece diretrizes gerais da Política Urbana e dá outras providências. Diário do Congresso Nacional, ano XLV, n. 126, 10 de outubro de 1990, p.10241-10249.

BRASIL. Lei n. 10257, de 10 de julho de 2001. Regulamenta os artigos 182 e 183 da Constituição Federal, estabelece diretrizes gerais da Política Urbana e dá outras providências. Disponível em: <www.planalto.gov.br>. Acesso em: 20 jan. 2018.

BRASIL. Lei n. 12608, de 10 de abril de 2012. Institui a Política Nacional de Proteção e Defesa Civil - PNPDEC; dispõe sobre o Sistema Nacional de Proteção e Defesa Civil -SINPDEC e o Conselho Nacional de Proteção e Defesa Civil - CONPDEC; autoriza a criação de sistema de informações e monitoramento de desastres; altera as Leis nos 12.340 , de 1ㅇ de dezembro de 2010, 10.257, de 10 de julho de 2001, 6.766, de 19 de dezembro de 1979, 8.239, de 4 de outubro de 1991, e 9.394, de 20 de dezembro de 1996; e dá outras providências.. Disponível em: <www.planalto.gov.br>. Acesso em: 10 jul. 2018.

BRASIL. Conselho da Cidade. Resolução Recomendada n. 34, de 01 de julho de 2005. Diário Oficial da União, 14 de julho de 2005, seção I. p.89.

CARDOSO, A. L. Reforma Urbana e planos diretores: avaliação da experiência recente. Cadernos IPPUR, Rio de Janeiro, ano XI, n.1 e 2, p.79-111, 1997.

CONSELHO DE ARQUITETURA E URBANISMO (CAU). Resolução n. 51. Atribuições Privativas de Arquitetos e Urbanistas. Disponível em: <http://www.caubr.gov.br/wp-content/uploads/2013/11/AFNFolderresolucao51.pdf>. Acesso em: 10 fev. 2018.

COSTA, L. A. M. O todo da parte: Urbanismo, Planejamento e o Processo Social de Construção da Cidade no Início do Século 20. Revista Pós, v. 19, n. 32, p. 136-157, dez. 2012.

DE GRAZIA, G. Estatuto da Cidade: Uma Longa História com Vitórias e Derrotas. In: OSÓRIO, L. M. (Org.) Estatuto da Cidade e Reforma Urbana: Novas Perspectivas para as Cidades Brasileiras. Porto Alegre: Sergio Antonio Fabris Editor, 2002. p.15-37.

FRAMPTON, K. História Crítica da Arquitetura Moderna. 2.ed. São Paulo: Martins Fontes, 2008. 529p.

INSTITUTO BRASILEIRO DE GEOGRAFIA E ESTATÍ́STICA (IBGE). Pesquisa de Informações Básicas Municipais - Munic 2015. Disponível em: https://ww2.ibge.gov.br/home/estatistica/economia/perfilmunic/2015/default.shtm Acesso em: 10 dez 2017.

INSTITUTO DE ARQUITETOS DO BRASIL (IAB). Planos Diretores para as cidades pequenas e médias do Brasil. Revista Arquitetura, Rio de Janeiro, n. 22, p.5-12, abr. 1964.

INSTITUTO DE ARQUITETOS DO BRASIL (IAB). s.HRu. sem. de habitação e reforma urbana. Revista Arquitetura, Rio de Janeiro, n. 15, p.17-24, set. 1963.

LEME, M. C. S. A Formação do Pensamento Urbanístico no Brasil, 1895-1965. In: LEME, M. C. S. (Org.). Urbanismo no Brasil 1895-1965. 2. ed. Salvador: EDUFBA, 2005. p.20-38.

MELLO, L. I. R. A. O governo das cidades. Boletim do Instituto de Engenharia, v. 10, n. 44, 1929.

RIBEIRO, C.; PONTUAL, V. A Reforma Urbana nos primeiros anos da década de 1960. Arquitextos, ano 10, v.109, n.7, jun. 2009.

SANTOS JR., O. A. Reforma Urbana: Por um novo modelo de planejamento e gestão das cidades. Rio de Janeiro: FASE / UFRJ-IPPUR, 1995.

SANTOS JR., O. A..; MONTANDON, D. T. Sínteses, Desafios e Recomendações. In: SANTOS JR., O. A.; MONTANDON, D. T. (orgs). Os Planos Diretores Municipais Pós-Estatuto da Cidade. balanço crítico e perspectivas. Rio de Janeiro: Letra Capital: Observatório das Cidades: IPPUR/UFRJ, 2011. p.27-56. 
SOUZA, M. L. Mudar a Cidade: Uma Introdução Crítica ao Planejamento e à Gestão Urbanos. 4. ed. Rio de Janeiro: Bertrand Brasil, 2006.

VILLAÇA, F. As Ilusões do Plano Diretor. São Paulo: Mimeo, 2005. 